\title{
DYNAMIC ENERGY MODELING OF AN EXPERIMENTAL BUILDING EQUIPPED WITH AN UNDERFLOOR AIR DISTRIBUTION (UFAD) SYSTEM
}

\author{
${ }^{1}$ Ahmed Cherif Megri and ${ }^{2}$ Yao Yu \\ ${ }^{1}$ Civil, Architectural and Environmental Engineering, CERT Research Center, \\ ${ }^{2}$ Department of Computational Science and Engineering, \\ North Carolina A and T State University, Greensboro, North Carolina, USA
}

Received 2014-01-30; Revised 2014-03-04; Accepted 2014-03-14

\begin{abstract}
In this study, experimental and simulation studies were performed in a building equipped with an UFAD system in order to investigate the applicability of a new approach designed for prediction of the energy consumption of a residential building with an UFAD system. In this approach, a zonal model, Pressurized zOnal Model with the Air diffuser (POMA), was coupled with a thermal jet model and integrated into a traditional multizone thermal model. The coupled model was verified experimentally. This integrated model has the ability to take into account the characteristics of an UFAD system and thus accurately simulate its energy consumption. A case study was carried out using both approaches: Multi-zone approach and the new developed integrated zonal/jet/multizone model. A quantitative comparison, in terms of energy demand of a building with an UFAD system, shows that the difference can reach $14 \%$ and thus indicates that the traditional multizone modeling approach is not appropriate to use for UFAD system in the building energy prediction.
\end{abstract}

Keywords: Energy Demand, UFAD, POMA, Zonal Model, Experiment, Thermostat Location

\section{INTRODUCTION}

The existing building energy simulation programs, such as (eQUEST, 2010; Trace700, 2010; EnergyPlus, 2011; Klein, 2000), have been proved to be appropriate to predict energy demands of overhead ventilation systems. They are not really suitable to be used for buildings associated with particular Heating, Ventilation and Air Conditioning (HVAC) systems, such as UnderFloor Air Distribution (UFAD) systems and displacement ventilation systems. These systems have been developed to replace the traditional overhead ventilation system, in certain situations, in order to improve the indoor thermal comfort, indoor air quality levels and/or to save energy (Griffith and Chen, 2004; Schiavon et al., 2011). In the case where an UFAD system is used, the entire zone is physically separated into two spaces, an occupied room space and a floor plenum space, by a raised floor. Conditioned airflow from an Air Conditioning (AC) unit is delivered to the floor plenum and then supplied to the occupied room above through floor diffusers (Fig. 1). Consequently, new energy demand prediction approaches based on the characteristics of these advanced ventilation systems need to be developed, in consideration of the poor prediction capacity of the existing multi-zone models used in the building energy prediction.

Multiple studies have been already developed to improve the prediction accuracy and the quality of building energy and demand computation with the assistance of detailed air modeling approaches. These new developments on advanced HVAC systems have participated in the improvement of energy simulation model prediction.

Corresponding Author: Ahmed Cherif Megri, Civil, Architectural and Environmental Engineering, CERT Research Center, North Carolina A and T State University, Greensboro, North Carolina, USA 


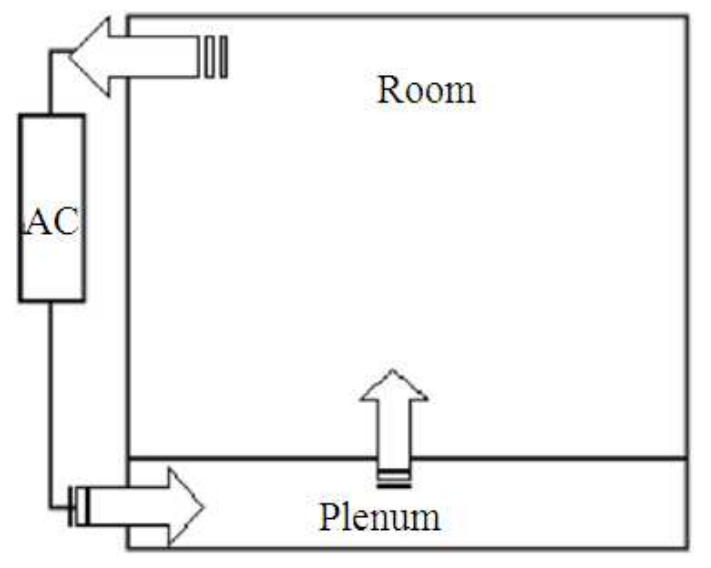

Fig. 1. Demonstration of an UFAD system

Griffith and Chen (2004) stated "the assumption that room air is well mixed may lead to significant errors in HVAC system sizing" and coupled the momentum equation to the zonal model to accurately predict hourly building loads of a single thermal zone. Zhai et al. (2002) demonstrated several efficient methods to integrate energy prediction into Computational Fluid Dynamics (CFD) models in order to improve the accuracy and the quality of building energy prediction. Bauman et al. (2006) investigated the primary pathways of UFAD systems for heat to be removed from a room in a cooling application. They found that, under cooling operation, a stratification produced by UFAD systems changes the dynamic characteristics of heat transfer and they stated that "Up to $40 \%$ of the total room cooling load is transferred into the supply plenum and only about $60 \%$ is accounted for by the return air extraction rate". Schiavon et al. (2011) proposed a simplified method to design building room cooling loads for UFAD systems, based on a number of EnergyPlus simulations and regression models. They demonstrated the differences in design cooling load calculation between UFAD and traditional well-mixed overhead systems and found that a peak cooling load of UFAD systems is $19 \%$ higher than an overhead cooling load.

Although the results of these researches regarding UFAD systems are available, most of them are focusing on the application of this system in commercial building and under cooling operation (Schiavon et al., 2011; Bauman et al., 2006; Schiavon et al., 2010; Alajmi and El-Amer, 2010). The researches regarding the application of UFAD systems in residential dwelling and/or under heating operation are very limited. In this study, the zonal model, Pressurized zOnal Model with the Air diffuser (POMA) (Haghighat et al., 2001; Lin et al., 1999; Megri and Yu, 2010), was coupled with a thermal jet model (Vialle and Blay, 1996). This coupled zonal model was verified experimentally and then integrated with a traditional multizone thermal model (ASHRAE Fundamentals, 2005), in order to improve the heating energy prediction of a building equipped with an UFAD system and also to take into account the characteristics of the UFAD systems and the thermostat location. A case study was carried out on a building associated with an UFAD system to demonstrate the importance of the new developed approach compared to the existing multizone thermal models through a comparative study.

\section{MODEL DESCRIPTION}

The zonal model POMA (Haghighat et al., 2001) coupled with a thermal jet model was used to predict the indoor air thermal behavior of zone equipped with an UFAD system. POMA is one of the most widespread zonal models used in building environment for indoor airflow and thermal behavior predictions (Haghighat et al., 2001; Megri et al., 2005; Megri and Haghighat, 2007; Yu and Megri, 2011). Its original modeling structure includes a mass conservation equation and an energy conservation equation, in addition to a power law model that substitutes the momentum equation. This model is especially suitable for natural convection problems, in which the indoor airflow and thermal behaviors are dominated by the impacts of buoyancy and gravity. Nevertheless, for the forced ventilation problems, corresponding additional sub-models have to be accordingly included and numerically interconnected in the zonal model (Heiselberg et al., 1998; Haghighat et al., 2001), in order to describe the physical phenomena corresponding to these forces. Generally, these additional models include jet flow models, thermal plume models and so on. Jet flow models are used to distribute cool or warm air into an indoor room space for both cooling and heating applications. Various models exist, depending on the jet characteristics (thermal/isothermal jet, free/wall jet, circular/plane/radial jet and horizontal/vertical jet). Thermal plume models are caused by indoor heat sources, such as people, convection heater and other HVAC equipment (Heiselberg et al., 1998). The models are numerous and dependent on different plume characteristics (circular/plane plume, wall/corner/multiple plume). In these additional models important parameters, including centerline 
flow velocity and temperature as well as trajectory/penetration length/throw, are represented using empirical equations that were usually obtained from both conservation equations and experiments. The centerline flow velocity and temperature represent the central velocity and temperature of the jet flow or thermal plume; and the trajectory/penetration length/throw represent the effective length of the jet flow or thermal plume. To simulate the indoor air thermal behavior of an UFAD system, a specified thermal jet flow model is used, whose details are shown below.

The thermal jet flow can be divided into three regions, shown in Fig. 2, determined by the dimensionless distance Y (Vialle and Blay, 1996) Equation 1:

$\mathrm{Y}=\frac{\mathrm{y}}{\sqrt{\mathrm{A}_{0}}}$

Where:

$\mathrm{A}_{0}\left(\mathrm{~m}^{2}\right)=$ The supply diffuser area;

$\mathrm{y}(\mathrm{m})=\mathrm{A}$ certain distance in the flow direction and known as trajectory or penetration length.

As shown in Fig. 2, in Region $1, \mathrm{Y}<\mathrm{Y} 1=2$, the flow is established; in Region $2, \mathrm{Y} 1=2<\mathrm{Y}<\mathrm{Y} 2=7$, the jet flow has a behavior similar to a plane jet; and in Region 3, $\mathrm{Y}>\mathrm{Y} 2=7$, the flow behaves as an axisymmetrical jet. The decay laws of centerline velocity and temperature are given in Table 1, which are determined by the Archimedes number (Vialle and Blay, 1996) Equation 2:

$\mathrm{Ar}=\frac{\mathrm{g} \beta\left(\mathrm{T}_{0}-\mathrm{T}_{\mathrm{s}}\right) \sqrt{\mathrm{A}_{0}}}{\mathrm{v}_{0}^{2}}$
Where:

$\mathrm{V}_{0}(\mathrm{~m} / \mathrm{s})=$ The initial supply air velocity from a diffuser

$\mathrm{T}_{0}\left({ }^{\circ} \mathrm{C}\right)=$ The initial supply air temperature

$\mathrm{T}_{\mathrm{s}}\left({ }^{\circ} \mathrm{C}\right)=$ The surrounding temperature

$\mathrm{A}_{0}\left(\mathrm{~m}_{2}\right)=$ The supply diffuser area

$\mathrm{g}\left(\mathrm{m} / \mathrm{s}^{2}\right)=$ The acceleration of gravity; and

$\beta(1 / \mathrm{K})=$ The expansion coefficient

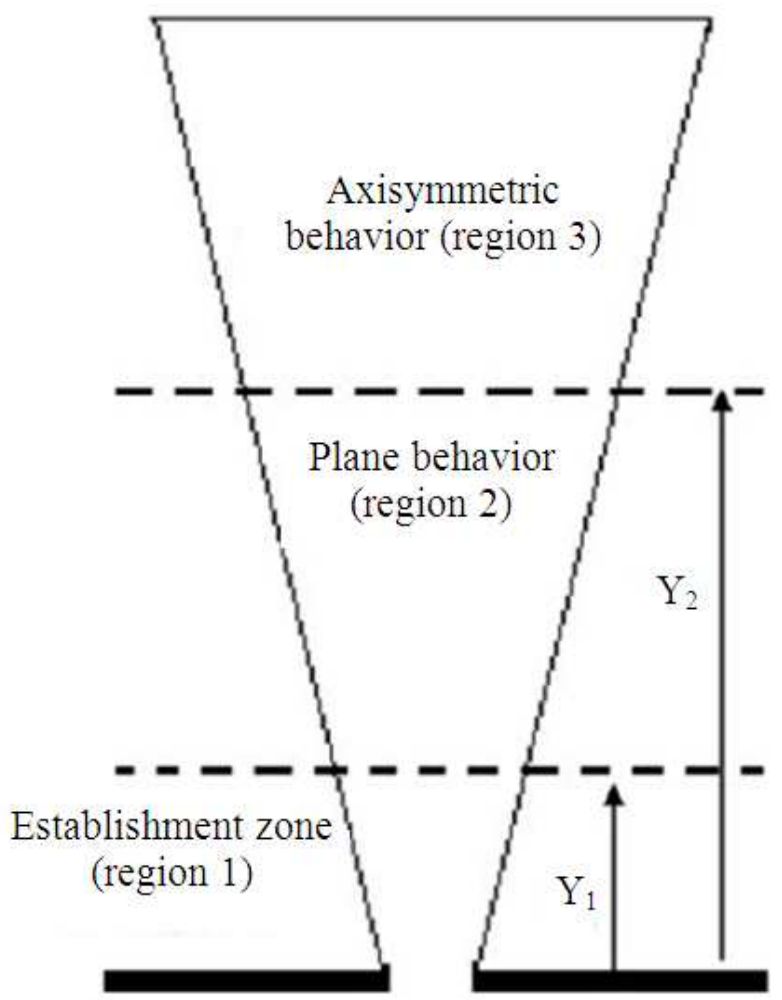

Fig. 2. Positive buoyancy jet (Vialle and Blay, 1996)

Table 1. Decay laws of centerline velocity and temperature (Vialle and Blay, 1996)

\begin{tabular}{|c|c|c|}
\hline Region & Velocity & Temperature \\
\hline Region $10<Y<Y 1 \quad \mathrm{Y} 1=2$ & $\mathrm{v}=\mathrm{v}_{0}$ & $\mathrm{~T}=\mathrm{T}_{0}$ \\
\hline Region 2 & $\frac{\mathrm{v}}{\mathrm{v}_{0}}=\left(\frac{\mathrm{Y}_{1}}{\mathrm{Y}}\right)^{\mathrm{b}_{2}}$ & $\frac{\mathrm{T}-\mathrm{T}_{\mathrm{s}}}{\mathrm{T}_{0}-\mathrm{T}_{\mathrm{s}}}=\left(\frac{\mathrm{Y}_{1}}{\mathrm{Y}}\right)^{\mathrm{b}_{2}}$ \\
\hline $\mathrm{Y} 1<\mathrm{Y}<\mathrm{Y} 2 \quad \mathrm{Y} 2=7$ & $b_{2}=0.28 \frac{0.22 r+0.07}{A r+0.07}$ & $b_{2}=0.28 \frac{5.4 A r+1.26}{A r+1.26}$ \\
\hline Region 3 & $\frac{\mathrm{v}}{\mathrm{v}_{0}}=\left(\frac{\mathrm{Y}_{1}}{\mathrm{Y}_{2}}\right)^{\mathrm{b}_{2}}\left(\frac{\mathrm{Y}_{2}}{\mathrm{Y}}\right)^{\mathrm{b}_{3}}$ & $\frac{\mathrm{T}-\mathrm{T}_{\mathrm{s}}}{\mathrm{T}_{0}-\mathrm{T}_{\mathrm{s}}}=\left(\frac{\mathrm{Y}_{1}}{\mathrm{Y}_{2}}\right)^{\mathrm{b}_{2}}\left(\frac{\mathrm{Y}_{2}}{\mathrm{Y}}\right)^{\mathrm{b}_{3}}$ \\
\hline $\mathrm{Y}>\mathrm{Y} 2 \mathrm{Y} 1=2 ; \mathrm{Y} 2=7$ & $\mathrm{~b}_{3}=0.73 \frac{0.203 \mathrm{Ar}+0.028}{\mathrm{Ar}+0.028}$ & $\mathrm{~b}_{2}=0.73 \frac{1.63 \mathrm{Ar}+0.06}{\mathrm{Ar}+0.06}$ \\
\hline
\end{tabular}


In this coupled zonal model (the thermal jet flow model and POMA), at the zones where the jet flows occur, the air mass flow rate is calculated based on the vertical thermal jet model using the jet flow rates which is defined as $\dot{\mathrm{m}}=\rho A v$, where $v(\mathrm{~m} / \mathrm{s})$ is the jet velocity defined in Table 1; $\rho\left(\mathrm{kg} / \mathrm{m}^{3}\right)$ is the air density; A $\left(\mathrm{m}^{2}\right)$ is the cross-sectional area between two zones; whereas at the other zones, POMA is utilized. Similarly, the centerline zone temperature of the jet is computed using the centerline temperature $T$ defined in Table 1; and the temperature of the other zones are still calculated using POMA.

\section{MODEL VERIFICATION}

Before the usage of the coupled zonal model, a model validation needs to be accomplished using experimentation. A room within a single dwelling house, which was the old day care center located in Laramie Wyoming (Fig. 3) was considered for the validation.

The size of the room is $4.62 \times 3.61 \times 2.39 \mathrm{~m}$. Since the height of the floor plenum for the UFAD system is $0.30 \mathrm{~m}$, the actual height of the room is $2.09 \mathrm{~m}$. This room has two external walls that are facing south and east. Two identical windows were located on the east and south walls. The dimensions of each are $1.57 \times 1.00 \mathrm{~m}$, as shown in Fig. 4. A floor air diffuser with the size of $0.53 \times 0.23 \mathrm{~m}$ is placed at the center of the room. One return grille $(0.84 \times 0.38 \mathrm{~m})$ is located on the north wall, near the ceiling (Fig. 4).

Forty-five type- $\mathrm{T}$ thermocouples were used to measure the room air temperature distribution, as shown in Fig. 5, in which TP1 to TP9 represent the 9 thermocouple poles (verticals) used to measure the vertical distributions of the air temperature. These 9 poles were uniformly distributed in the room as shown in Fig. 5 (d) and on each vertical, five thermocouples were attached to the pole and distributed evenly.

Boundary conditions, including the measured room interior surface temperatures and the measured supply air temperature and velocity of the diffuser are shown in the Table 2.

The coupled zonal model with the zone subdivision, $5 \times 5 \times 8$ ( 200 zones), is used to predict the indoor thermal behavior of the room air-conditioned using an UFAD system. Figure $\mathbf{6}$ shows the vertical temperature distributions of the 9 poles obtained by both the coupled zonal model and the experimentation. In this figure, $\mathrm{T}$ $\left({ }^{\circ} \mathrm{C}\right)$ is the predicted/experimental air temperature; Tin $\left({ }^{\circ} \mathrm{C}\right)$ is the initial supply air temperature which is $32.22^{\circ} \mathrm{C} ; \mathrm{z}(\mathrm{m})$ is the elevation from the raised floor; and $\mathrm{H}(\mathrm{m})$ is the height of the room space, which is $2.09 \mathrm{~m}$.

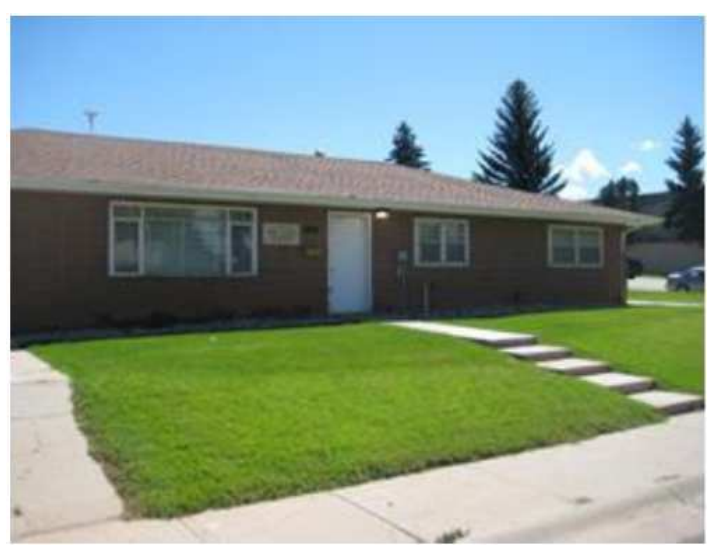

Fig. 3. Experimental building for the validation

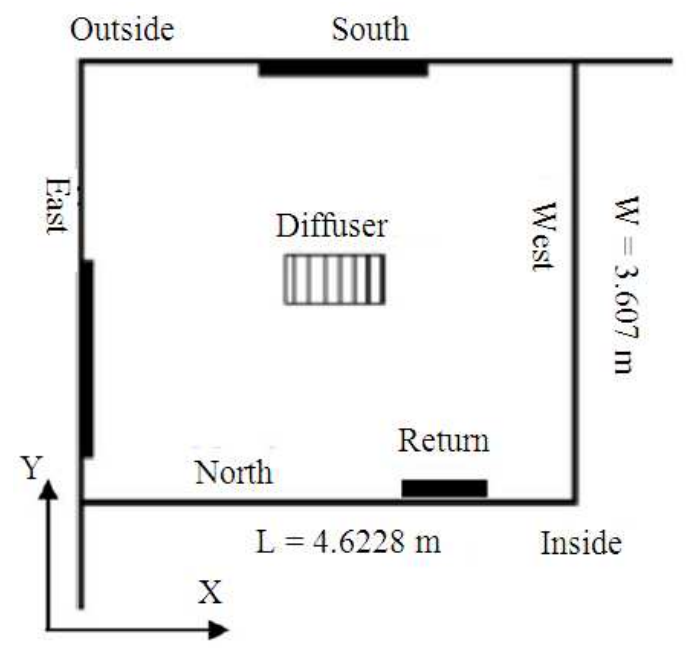

(a)

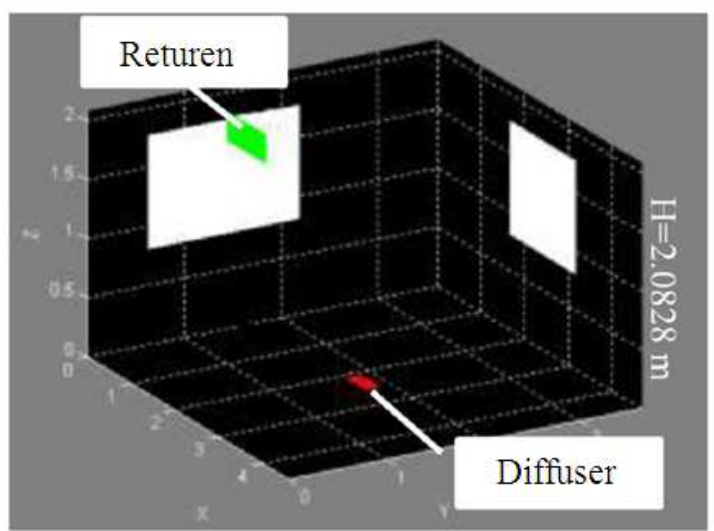

(b)

Fig. 4. Experimental building for the validation (a) top view; (b) 3-D view 


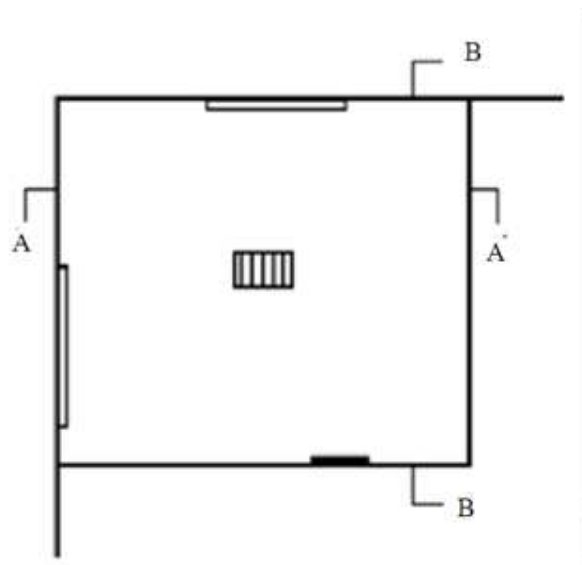

(a)

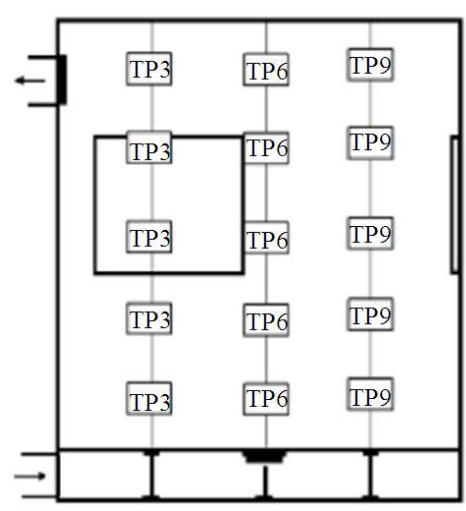

(c)

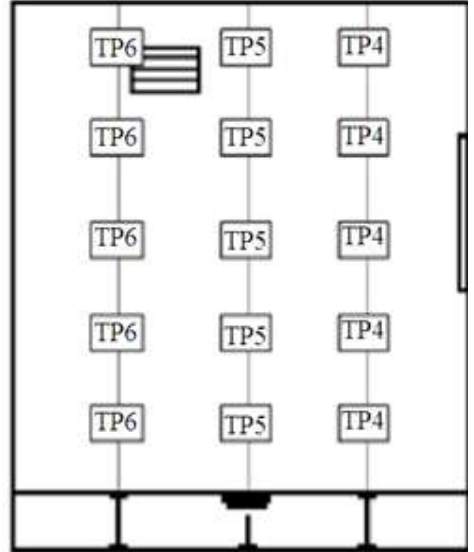

(b)

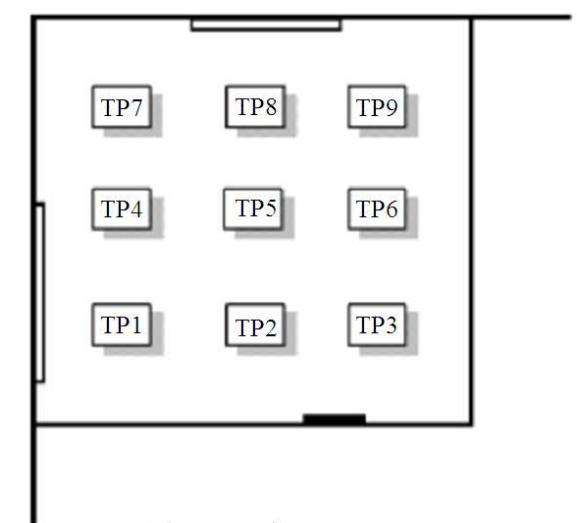

(d)

Fig. 5. Thermocouple layout (a) section insrruction (b) section A-A (c) section B-B (d) top view
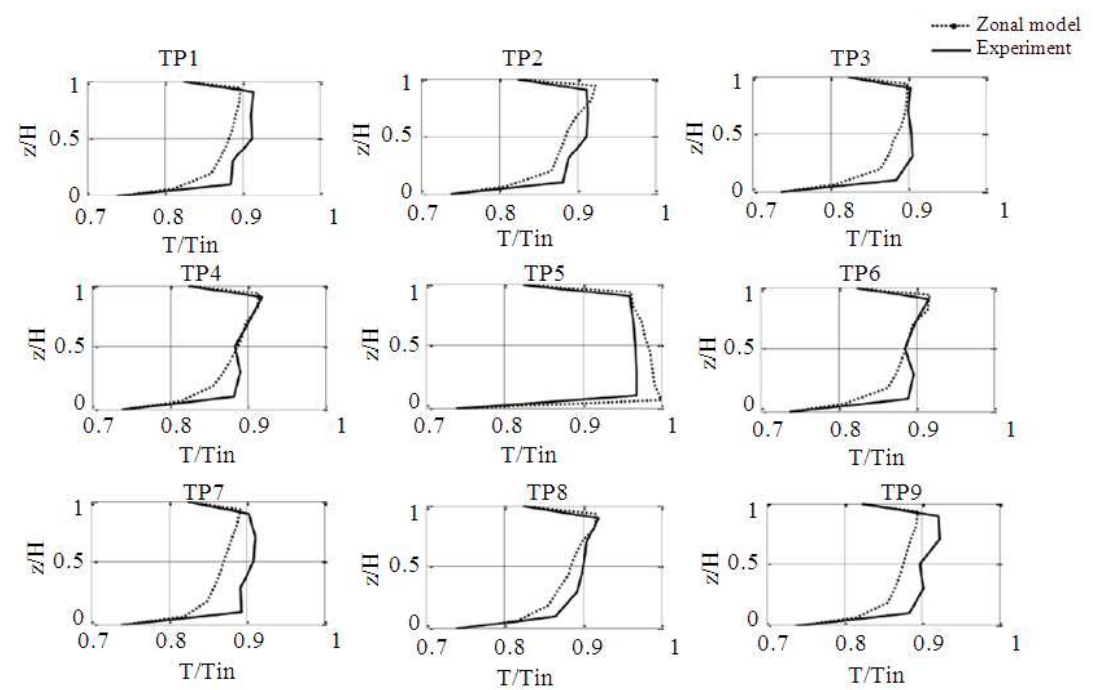

Fig. 6. Comparison between the coupled zonal model and experiment in terms of vertical temperature distribution 
Table 2. Boundary condition used for the validation

\begin{tabular}{llllllllll}
\hline & $\begin{array}{l}\text { North } \\
{\left[{ }^{\circ} \mathrm{C}\right]}\end{array}$ & $\begin{array}{l}\text { South } \\
{\left[{ }^{\circ} \mathrm{C}\right]}\end{array}$ & $\begin{array}{l}\text { East } \\
{\left[{ }^{\circ} \mathrm{C}\right]}\end{array}$ & $\begin{array}{l}\text { West } \\
{\left[{ }^{\circ} \mathrm{C}\right]}\end{array}$ & $\begin{array}{l}\text { Ceiling } \\
{\left[{ }^{\circ} \mathrm{C}\right]}\end{array}$ & $\begin{array}{l}\text { Floor } \\
{\left[{ }^{\circ} \mathrm{C}\right]}\end{array}$ & $\begin{array}{l}\text { East window } \\
{\left[{ }^{\circ} \mathrm{C}\right]}\end{array}$ & $\begin{array}{l}\text { South window } \\
{\left[{ }^{\circ} \mathrm{C}\right]}\end{array}$ & $\begin{array}{l}\text { Supply air } \\
{\left[{ }^{\circ} \mathrm{C}\right]}\end{array}$ \\
\hline Temperature & 27.99 & 20.92 & 21.13 & 26.88 & 26.51 & 23.74 & 26.23 & 25.89 & 32.22 \\
\hline
\end{tabular}

Diffuser air flow velocity: $0.635 \mathrm{~m} \mathrm{sec}^{-1}$

As shown in Fig. 6, the coupled zonal model produces a reasonably good result compared with the experimental data, which demonstrates that the zonal model POMA coupled with the specified thermal jet model is able to predict the characteristics of the indoor air, such as the temperature distribution within the conditioned room using an UFAD system.

\section{CASE STUDY}

In the case study, the integrated model (the coupled zonal model integrated with the multizone thermal model) was used to predict the heating energy demand of a room with an UFAD system.

\subsection{Basic Building Conditions}

A room in the single dwelling house shown in Fig. 3 was considered for this study (the experimental instrumented room). The basic conditions of this room were described preciously (Fig. 4) in the section 3, including the dimensions of the room, the height of the floor plenum and the information regarding the supply diffuser and the return grille. This room has two identical windows on the east and south walls with an area of 1.57 $\mathrm{m}^{2}$ each (U-value $1.4 \mathrm{~W} / \mathrm{m}^{2} \mathrm{~K}$; Solar Heat Gain Coefficient (SHGC) 0.59; no internal and external shading device). The thermal characteristics of the four walls, floor area and ceiling are presented in the Table 35. The local outside temperature and horizontal solar radiation are displayed in the Fig. 7 and 8 respectively. An UFAD system was used in this room for the heating season. No internal gains were considered in this study. This room was geometrically subdivided into 200 zones $(5 \times 5 \times 8$ mesh grids) for the simulation performed using the coupled zonal model. The simulations were carried out, neglecting the air leakage and air heat storage effects. The thermostat set point temperature is maintained as a constant value, $20^{\circ} \mathrm{C}$.

\subsection{The Predictive Model for the Energy Demand, for a Dwelling House Equipped with an UFAD System}

When an UFAD system is used for a space heating, the raised floor physically divides the entire space into two separated enclosures, a room space and a floor plenum space (Fig. 9). For energy and load simulation, these two spaces need to be treated separately and the multizone model will not be recommended to be used for the prediction of the thermal behavior of the room space, because of the presence of thermal stratification within the space. As shown in the Fig. 9, the energy demand of the UFAD system, $\mathrm{q}_{\text {system, }}$ is expressed as Equation 3 to 5:

$$
\begin{aligned}
& \mathrm{q}_{\text {in }}=\mathrm{q}_{\text {system }}+\mathrm{q}_{\text {out }},[\mathrm{W}] \\
& \mathrm{q}_{\text {in }}=\mathrm{q}_{\text {loss } 1}+\mathrm{q}_{\text {in }}^{\prime} ; \mathrm{q}_{\text {in }}^{\prime}=\mathrm{q}_{\text {loss } 2}+\mathrm{q}_{\text {out }},[\mathrm{W}] \\
& \text { so } \mathrm{q}_{\text {system }}=\mathrm{q}_{\text {loss } 1}+\mathrm{q}_{\text {loss } 2},[\mathrm{~W}]
\end{aligned}
$$

$\mathrm{q}_{\text {in }}(\mathrm{W})=$ The rate of heat transfer going into the plenum

$\mathrm{q}_{\text {out }}(\mathrm{W})=$ The rate of heat transfer going out from the room

$\mathrm{q}_{\text {loss }}(\mathrm{W})=$ The rate of the heat loss from the plenum

$\mathrm{q}_{\text {loss } 2}(\mathrm{~W})=$ The rate of heat loss from the room

$\mathrm{q}_{\text {in }}^{\prime}(\mathrm{W})=$ the rate of heat transfer from the plenum to the room space through floor diffusers and the raised floor construction

$\mathrm{q}_{\text {system }}(\mathrm{W})=$ The rate of heat generated by an Air Conditioning (AC) unit

For the energy demand computation, the developed coupled zonal model is used for the room space; whereas the multizone model is used for the plenum.

\subsection{Description of the Modeling Approach}

The validated coupled zonal model was integrated to the multizone thermal model in order to estimate the hourly heating energy demands of an enclosure equipped with an UFAD system and to quantify the impact of the thermostat location on the heating demand of a single dwelling house. The thermal model consists of energy balance equations, including the room air heat balance equation, the room interior surface heat balance equation and the room exterior surface heat balance equation. These equations involve heat transfer by convection, conduction and radiation (ASHRAE Fundamentals, 2005). 
Ahmed Cherif Megri and Yao Yu / American Journal of Engineering and Applied Sciences 7 (1): 23-35, 2014

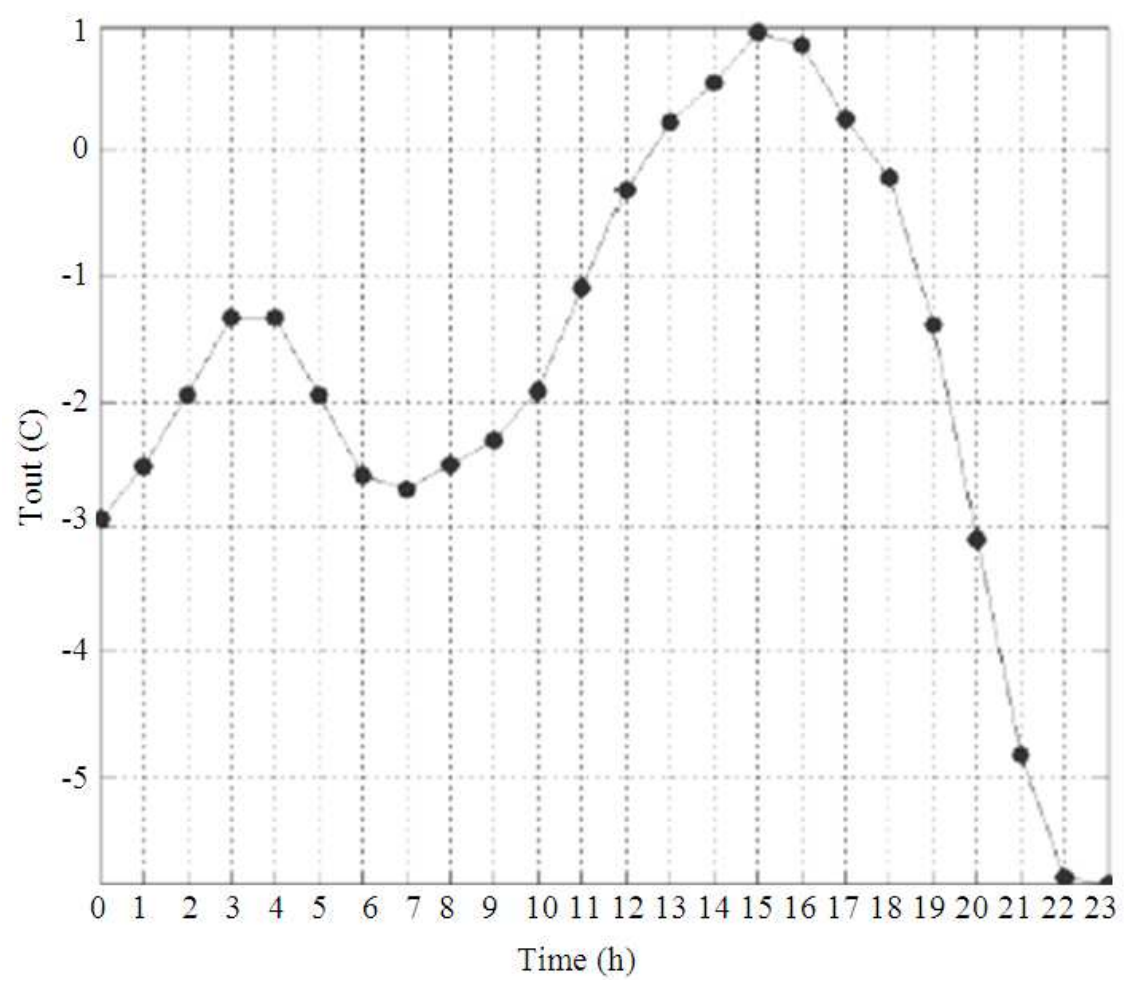

Fig. 7. Outdoor temperatures

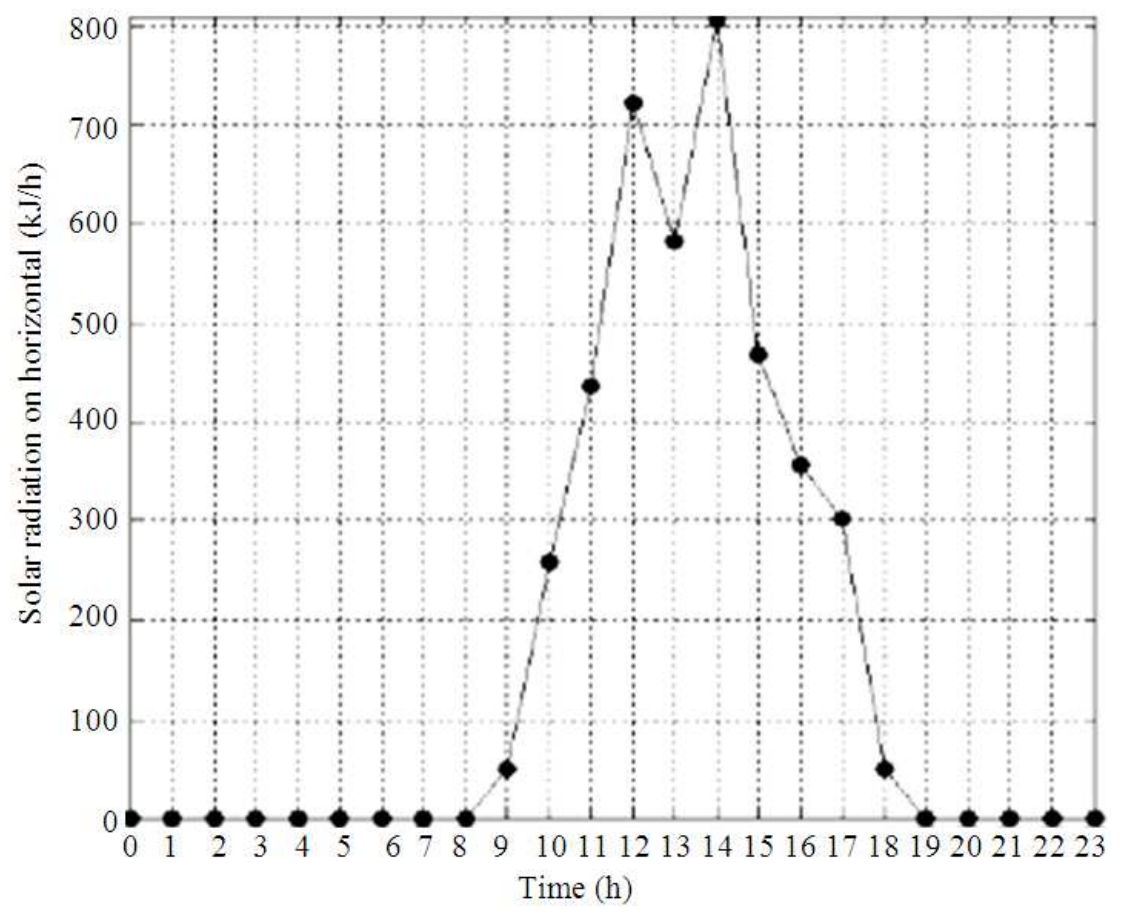

Fig. 8. Solar radiation on horizontal 


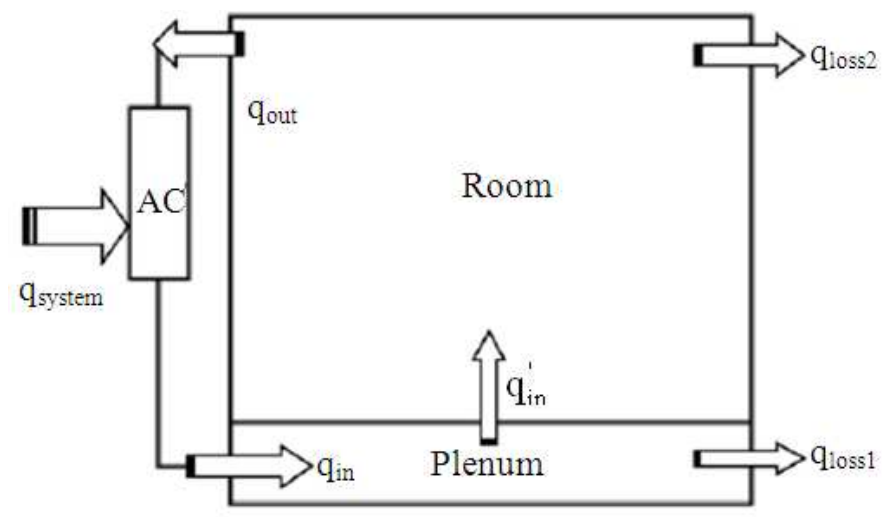

Fig. 9. Energy balance demonstration of UFAD system

Table 3. External wall characteristics

\begin{tabular}{|c|c|c|c|c|c|c|}
\hline \multirow[b]{2}{*}{ External walls } & \multirow[b]{2}{*}{ Area $\left(\mathrm{m}^{2}\right)$} & \multirow{2}{*}{$\begin{array}{l}\text { U-value } \\
\left(\mathrm{W} / \mathrm{m}^{2} \mathrm{~K}\right)\end{array}$} & \multicolumn{2}{|c|}{ Solar absorptance } & \multicolumn{2}{|c|}{ Convective heat transfer coefficient $\left(\mathrm{kJ} / \mathrm{h} \mathrm{m}^{2} \mathrm{~K}\right)$} \\
\hline & & & Inside & Outside & Inside & Outside \\
\hline South & 11.04 & 0.339 & 0.75 & 0.3 & 15.12 & 64 \\
\hline East & 8.61 & 0.339 & 0.75 & 0.3 & 15.12 & 64 \\
\hline
\end{tabular}

Table 4. Internal wall characteristics

\begin{tabular}{|c|c|c|c|c|c|c|}
\hline \multirow[b]{2}{*}{ Internal walls } & \multirow[b]{2}{*}{ Area $\left(\mathrm{m}^{2}\right)$} & \multirow{2}{*}{$\begin{array}{l}\text { U-value } \\
\left(\mathrm{W} / \mathrm{m}^{2} \mathrm{~K}\right)\end{array}$} & \multicolumn{2}{|c|}{ Solar absorptance } & \multicolumn{2}{|c|}{ Convective heat transfer coefficient $\left(\mathrm{kJ} / \mathrm{h} \mathrm{m}^{2} \mathrm{~K}\right)$} \\
\hline & & & Inside & Outside & Inside & Outside \\
\hline North & 11.04 & 0.652 & 0.6 & 0.6 & 15.12 & 15.12 \\
\hline West & 8.61 & 0.652 & 0.6 & 0.6 & 15.12 & 15.12 \\
\hline
\end{tabular}

Table 5. Floor and ceiling characteristics

\begin{tabular}{|c|c|c|c|c|c|c|}
\hline & \multirow[b]{2}{*}{ Area $\left(\mathrm{m}^{2}\right)$} & \multirow{2}{*}{$\begin{array}{l}\text { U-value } \\
\left(\mathrm{W} / \mathrm{m}^{2} \mathrm{~K}\right)\end{array}$} & \multicolumn{2}{|c|}{ Solar absorptance } & \multicolumn{2}{|c|}{ Convective heat transfer coefficient $\left(\mathrm{kJ} / \mathrm{h} \mathrm{m}{ }^{2} \mathrm{~K}\right)$} \\
\hline & & & Inside & Outside & Inside & Outside \\
\hline Raised floor & 16.67 & 1.671 & 0.80 & 0.40 & 14.544 & 18.0 (Plenum) \\
\hline Floor & 16.67 & 0.313 & 0.80 & - & 18.0 (Plenum) & - \\
\hline Ceiling & 16.67 & 0.233 & 0.35 & 0.75 & 14.544 & 14.544 (Attic) \\
\hline
\end{tabular}

The integration between the coupled zonal model and the multizone thermal model has been accomplished considering the fact that the boundary surface temperatures needed for the zonal model are predicted by the thermal model. This integration allows the coupled zonal model to estimate the indoor room temperature distribution and the room airflow using the boundary conditions predicted by the multizone thermal model. This integrated model is able to provide corresponding indoor thermal responds for various outdoor weather conditions over time. Additionally, unlike the traditional multizone thermal model, a detailed performance and analysis of the indoor thermal behavior and air flow pattern can be obtained using this integrated model. Consequently, an accurate energy model has been established based on this detailed room thermal description, in which more factors that are able to impact the building energy consumption can be considered, such as the thermostat location, the asymmetric radiation, hot surfaces and others, which are difficult to consider in the traditional multizone thermal model used in building energy simulation.

Although the integration procedure is different from system to system, depending on the system type and its characteristics, a general integration approach is displayed in Fig. 10. As shown in this figure, a parameter that has an effect on energy prediction is adjusted numerically in order to meet the room requirement, such as a specific local room air temperature or a specified thermal comfort level. 


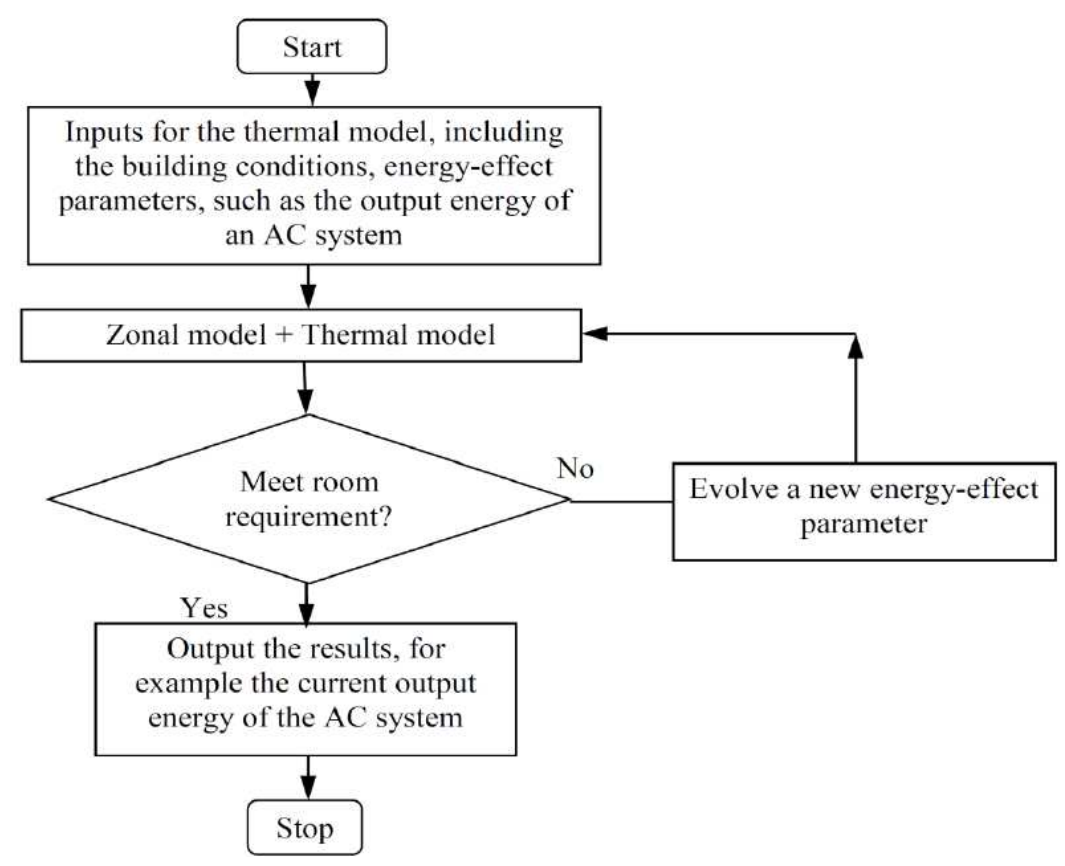

Fig. 10. General integration procedure

This parameter represents the most sensitive factor that can directly or indirectly affect the building energy prediction. This parameter may be the supply air temperature or the supply air flow for a forced ventilation system, or the electrical energy input for an electric floor radiation system. Once the room requirement is met, the energy demands of the Air Conditioning (AC) system can be determined based on the current value of the parameter selected.

Specifically, the simulation procedure to determine the energy demand of a dwelling house with an UFAD system using the integrated model is shown below.

Step 1: Selection of the supply air temperature for the room space.

Any reasonable supply air temperature for a residential house under heating operation can be used, such as $32^{\circ} \mathrm{C}$. Nevertheless, in consideration of the characteristics of UFAD systems and the thermal comfort of occupants (ANSI/ASHRAE Standard 55, 2004), a constant supply air temperature of $29.4^{\circ} \mathrm{C}$ from the floor diffuser was used.

Step 2: Location of the thermostat

Typically, the thermostat location depends on the grid mesh of the space detailed (zonal or CFD) model. Any zone of the grid mesh of the room is a potential thermostat location. In our case, any of the 200 zones may be considered as a thermostat location.

Step 3: Determination of the Design Temperature Distribution (DTD)

In order to be able to use the integrated model to predict the heating energy demands, a new concept was introduced, which represents an intended indoor temperature distribution. This intended temperature distribution called "Design Temperature Distribution" (DTD) that can be used to determine the hourly energy demands of the building. The DTD is sensitive to many factors, such as the location of the thermostat, the type of HVAC system and so on. Different HVAC systems and various thermostat locations may have distinct DTDs. The approach to determine the DTD of an UFAD system is shown below.

The input information of the thermal model are similar to building energy simulation programs, such as weather condition, building geometry and areas, building location and orientation, opening characteristics and location and so on. The supply airflow ventilation rate to the room space is adjusted (increased or decreased) gradually. As long as, the airflow supply ventilation rate changes, the room thermal behavior, i.e., the room air temperature distribution changes as well. Therefore, for each ventilation rate, there is a corresponding room air 
temperature distribution profile predicted by the coupled zonal model. The air temperature of the zone where the thermostat is located is observed carefully. A soon as, this zone air temperature is equal to the thermostat set point temperature (the set point is considered as $20^{\circ} \mathrm{C}$ in the case study of this study), the current air temperature distribution profile will be regarded as the DTD and the corresponding supply ventilation rate $\mathrm{M}_{v}$ is also determined.

Step 4: Calculation of the hourly heating energy demand Once the DTD is obtained in the step 3, the energy demand (heat loss) q qoss2 can be estimated using the equation:

$\mathrm{q}_{\text {loss } 2}=\mathrm{m}_{\mathrm{v}} \operatorname{cp}\left(\mathrm{T}_{\text {in }}-\mathrm{T}_{\text {out }}\right),[\mathrm{W}]$

where, $\mathrm{M}_{v}(\mathrm{~kg} / \mathrm{s})$ is the supply ventilation rate from the diffuser, which is determined in the step $3 ; \mathrm{cp}(\mathrm{J} / \mathrm{kg} \mathrm{K})$ is the specific heat; $\mathrm{T}_{\text {in }}\left({ }^{\circ} \mathrm{C}\right)$ is the supply air temperature that is a constant and equal to $29.4^{\circ} \mathrm{C}$ selected in Step 1; and $\mathrm{T}_{\text {out }}\left({ }^{\circ} \mathrm{C}\right)$ is the return air temperature based on the current DTD, which is the air temperature of the zone that is close to the return opening. $T_{\text {out }}$ is sensitive to many factors, such as thermostat location, diffusers locations, building materials and type of construction, weather condition and so on.

Step 5: Calculation of the total heating energy demand $\left(\mathrm{q}_{\text {loss } 1}+\mathrm{q}_{\text {loss } 2}\right)$ of the entire space (room space+floor plenum space shown in the Fig. 9).

To determine the heating energy demand of the building where a floor plenum space is used for heating, a similar procedure as mentioned in the steps 3 and 4 can be applied. In this procedure, instead of the supply ventilation rate, the supply air temperature of the floor plenum from the outlet of the air conditioning unit is regarded as the parameter that needs to be adjusted gradually. The ventilation rate that was determined in the step 3 and the leaving air temperature of the floor plenum (the supply air temperature of the room space) that was determined in the step 1 are known. Therefore, for each supply air temperature of the floor plenum, a corresponding leaving air temperature of the floor plenum can be predicted. Then, using the Equation 6, the heating energy demand $\left(\mathrm{q}_{\text {loss } 1}\right)$ of the floor plenum space can be calculated. Finally, the total heating demand ( $\left.\mathrm{q}_{\text {loss } 2}\right)$ of the entire space can be computed by the summation of the energy demands for both the room space and the floor plenum.
These steps are repeated for various thermostat locations and for every time step.

\section{RESULT AND DISCUSSION}

The heating energy demand result is displayed in the Fig. 11, in which "Multi Zone Rm+Plnm" represents the total energy demand of the room and plenum, which is equal to $\mathrm{q}_{\text {loss } 1}+\mathrm{q}_{\mathrm{loss} 2}$ (Equation 5) and calculated using the original multizone thermal model to both the room space and floor plenum respectively. "Typical thermostat location Rm+Plnm" represents the energy demand summation of the room and plenum when the thermostat is located at the typical position (Fig. 12), by applying the integrated model to the room space and the traditional thermal model to the plenum. "Different thermostat locations Rm+Plnm" represents the different energy demand summations of the room and the plenum according to different thermostat positions, when using the integrated model to the room space and the traditional thermal model to the plenum. Figure 12 shows the typical thermostat location which is on the north wall, below the return grille, approximately $1.5 \mathrm{~m}$ above the raised floor and $3.3 \mathrm{~m}$ away from the east wall.

As shown in the Fig. 11, the heating energy demand decreases at around 9:00 AM (solar time) and reaches the minimum at 14:00 AM. In fact, the magnitude of the solar radiation plays a significant role in the heating energy demands of the UFAD system in this room. As shown in the Fig. 8, the strength of the solar radiation increases from zero at 8:00 AM to reaches the maximum value at around 14:00 AM. During this time period, the solar energy is transmitted into the room through the two windows located on the east and south walls and thus offsets the requirement of heating energy of this room.

Additionally, as shown in Fig. 11, different thermostat locations account for various energy demands. Since the actual indoor air temperature distribution is not uniform, the energy demand would be different when the thermostat position changes within the same room. The result of "Multi zone $\mathrm{Rm}+\mathrm{Plnm}$ " is different from the "Typical thermostat location Rm+Plnm" result, demonstrating that the multizone thermal model is not able to accurately predict the heating energy demands of the UFAD system because of the presence of thermal stratification in the room. Therefore, an advanced integrated zonal model, need to be used, in order to take into account the detailed indoor temperature and airflow distributions in the energy prediction. 
Ahmed Cherif Megri and Yao Yu / American Journal of Engineering and Applied Sciences 7 (1): 23-35, 2014

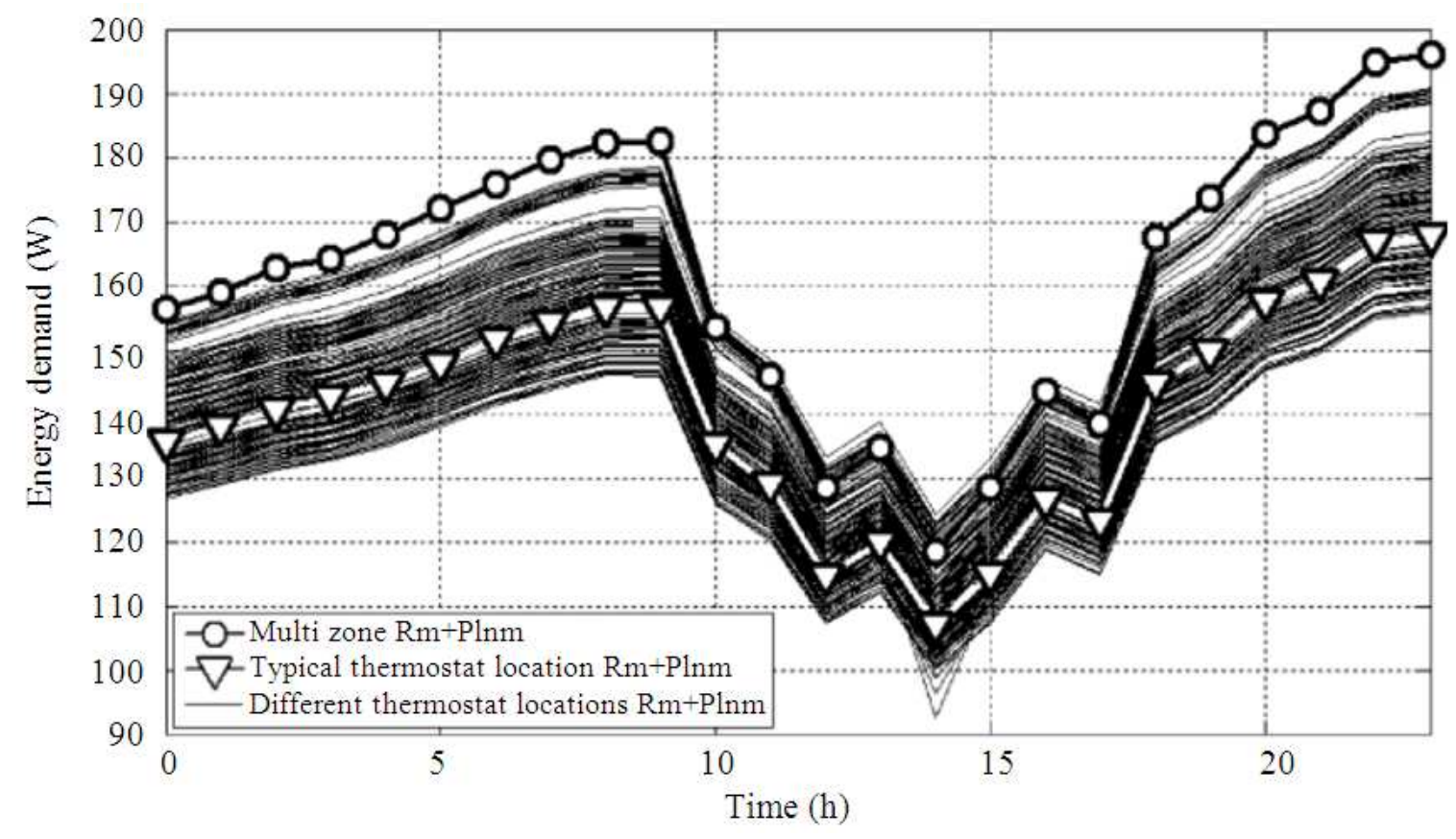

Fig. 11. Energy demand comparisons

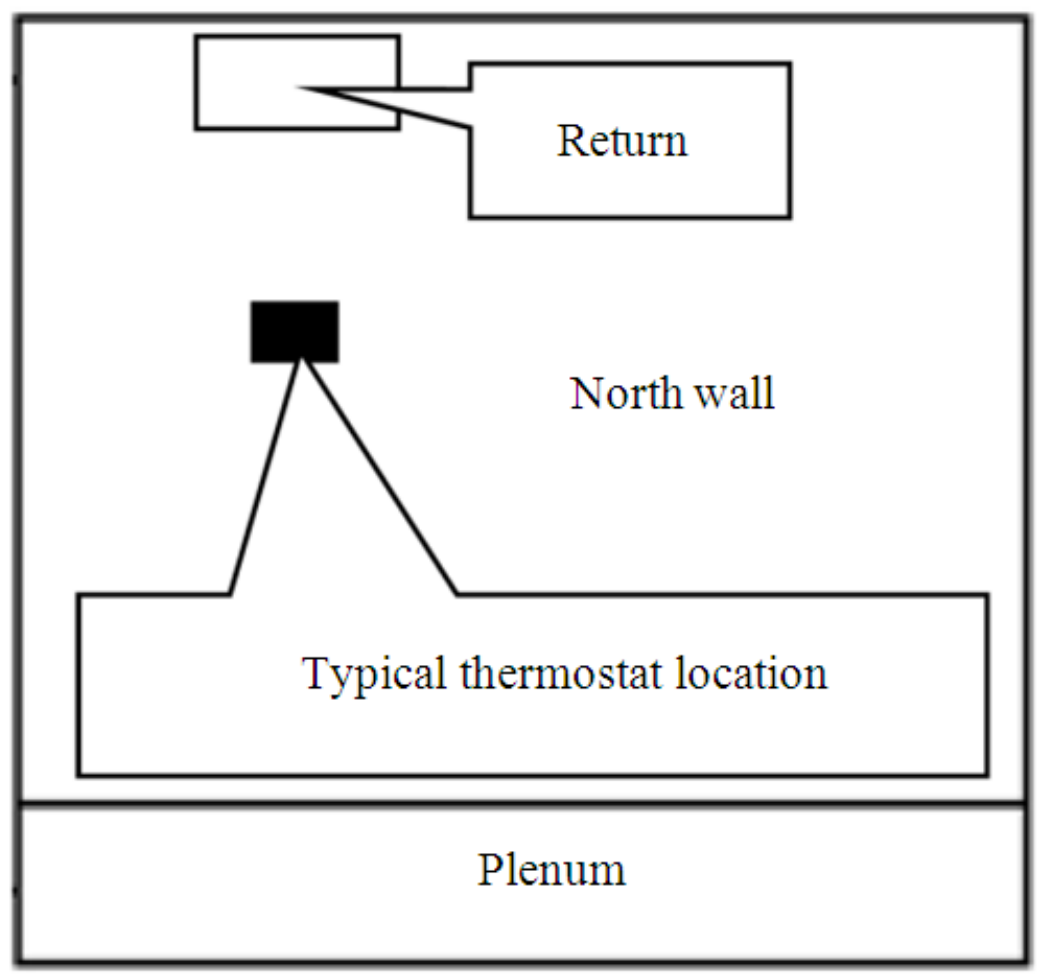

Fig. 12. Typical thermostat location 


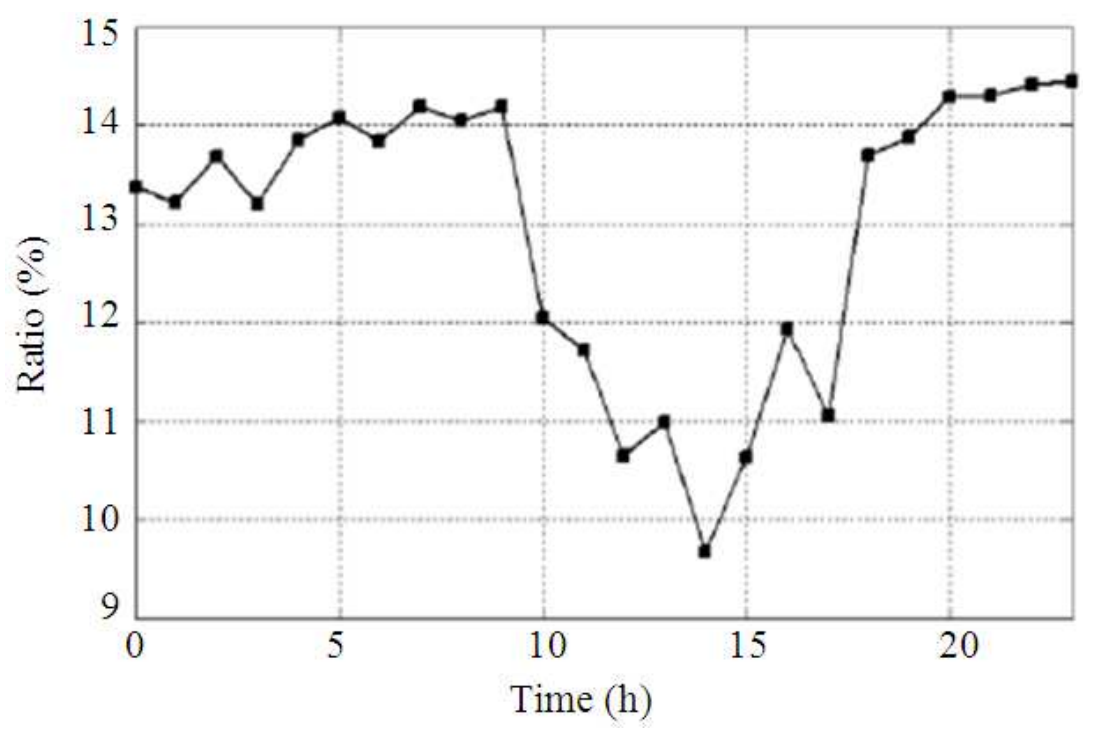

Fig. 13. Energy demand ratio

Figure 13 shows the ratio of the heating demand of "Multi zone Rm+Plnm" to "Typical thermostat location Rm+Plnm". This figure indicates a difference of $14 \%$ in term of heating energy for a single dwelling house equipped with an UFAD system. This potential saving is only due to the usage of the integrated model in building energy/load prediction, since this model has more representation of the actual building thermal and airflow conditions.

\section{CONCLUSION}

The zonal model POMA has been coupled with a thermal jet model to predict single dwelling house air thermal behavior under an UFAD heating system. This coupled zonal model has been evaluated using experimentation. The result of this validation has shown that the coupled model has the capability of predicting air thermal behavior within a residential house, when an UFAD system is used for heating. Then, this coupled zonal model has been integrated with the traditional multizone thermal model, in order to improve the heating energy demand prediction of a single dwelling house equipped with an UFAD system. The case study using the integrated model have revealed the importance of detailed room air models for predicting building energy demands and have demonstrated the needs of substituting the multizone model.
Specifically, we conclude that:

- The traditional well-mixed method is not appropriate to use for UFAD systems in building energy demand prediction. In the case studied, the heating energy predicted by multizone thermal model is $14 \%$ over estimated. Therefore, advanced and more detailed models, such as CFD or zonal model, need to be used.

- The different thermostat locations indeed affect the building energy demand/consumption. As a matter of fact, the thermostat location is an important factor, which influences building energy demands, room ventilation requirements, human thermal comfort and even the effectiveness of HVAC systems. Therefore, designers or researchers should pay more attention to the impacts of thermostat location in building.

\section{ACKNOWLEDGEMENT}

This project has been performed under an EPA fund. We gratefully acknowledge their support.

\section{REFERENCES}

Alajmi, A. and W. El-Amer, 2010. Saving energy by using Underfloor-Air-Distribution (UFAD) system in commercial buildings. Energy Convers. Manage., 51: 1637-1642.

DOI: 10.1016/j.enconman.2009.12.040 
ANSI/ASHRAE Standard 55, 2004. Thermal environmental conditions for human occupancy. Atlanta, GA.

ASHRAE Fundamentals, 2005. ASHRAE Handbook: Fundamentals. American Society of Heating, Refrigeration and Air-Conditioning Engineers, Inc., Atlanta.

Bauman, F.S., H. Jin and T. Webster, 2006. Heat transfer pathways in Underfloor Air Distribution (UFAD) systems. ASHRAE Trans., 112: 567-580.

EnergyPlus, 2011. EnergyPlus energy simulation software. Energy Efficiency and Renewable Energy, US Department of Energy.

eQUEST, 2010. Introductory Tutorial, Version 3.64, James J. Hirsch and Associates.

Griffith, B. and Q. Chen, 2004. Framework for coupling room air models to heat balance model load and energy. HVAC R Res., 10: 91-111. DOI: 10.1080/10789669.2004.10391094

Haghighat, F., Y. Lin and A.C. Megri, 2001. Development and validation of a zonal modelPOMA. Build. Environ., 36: 1039-1047. DOI: 10.1016/S0360-1323(00)00073-1

Heiselberg, P., S. Murakami and C.A. Roulet, 1998. Ventilation of large spaces in buildings analysis and prediction techniques. Aalborg University.

Lin, Y., A.C. Megri and F. Haghighat, 1999. Zonal model-a new generation of combined airflow and thermal model. Proceedings of Indoor Air, (IA '99) Edinburgh, Scotland.

Megri, A.C. and F. Haghighat, 2007. Zonal modeling for simulating indoor environment of buildings: Review, recent developments and applications. HVAC R Res., 13: 887-905. DOI: 10.1080/10789669.2007.10391461

Megri, A.C., M. Snyder and M. Musy, 2005. Building zonal thermal and airflow-A review. Int. J. Ventilat., 4: $177-188$
Megri, A.C. and Y. Yu, 2010. New calibrated zonal model for temperature, pressure and airflow predictions. Proceedings of the 10th Rehva World Congress Sustainable Energy Use in Buildings, May 9-12. Antalya, Turkey.

Schiavon, S., K.H. Lee, F. Bauman and T. Webster, 2010. Influence of raised floor on zone design cooling load in commercial buildings. Energy Build., 42: 1182-1191. DOI: 10.1016/j.enbuild.2010.02.009

Schiavon, S., K.H. Lee, F. Bauman and T. Webster, 2011. Simplified calculation method for design cooling loads in Under Floor Air Distribution (UFAD) systems. Energy Build., 43: 517-528. DOI: 10.1016/j.enbuild.2010.10.017

Trace700, 2010. Building energy and economic analysis user's manual. Version 6.2. Trane.

Klein, S.A., TRNSYS, 2000. TRNSYS, a Transient System Simulation Program. 1st Edn., Solar Energy Laborataory, University of Wisconsin-Madison, Madison, Wis., pp: 536.

Vialle, P. and D. Blay, 1996. Decay laws in the case of 3D vertical free jets with positive buoyancy. Yokohama, Japan.

Yu, Y. and A.C. Megri, 2011. Development and application of a new dynamic zonal model (POMA+). Proceedings of the 12th International Conference on Air Distribution in Rooms, June 1922, Trondheim, Norway.

Zhai, Z., Q. Chen, P. Haves and J.H. Klems, 2002. On approaches to couple energy simulation and computational fluid dynamic programs. Build. Environ., 37: 857-864. DOI: 10.1016/S03601323(02)00054-9 